\title{
Postnatal Development of Hepatic Innate Immune Response
}

\author{
Valerie Le Rouzic, ${ }^{1}$ Jennifer Corona, ${ }^{1}$ and Heping Zhou ${ }^{1,2}$
}

\begin{abstract}
The liver is an immunocompetent organ that plays a key role in the immune response to infections, and the development of hepatic immune function during early postnatal stages has not been thoroughly characterized. This study analyzed the constitutive expression of complement factors, namely $\mathrm{C} 3$ and $\mathrm{C} 9$, and pattern recognition receptors, namely CD14, toll-like receptor (TLR)4, and lipopolysaccharide binding protein (LBP), in the liver of postnatal day (P)1, P21, and P70 rats, and compared the kinetics of induction of cytokines and chemokines in the liver of $\mathrm{P} 1$ and $\mathrm{P}$ 21 animals. Our studies found that while the mRNA expression of C3, C9, CD14, and TLR-4 was lower in P1 animals, the mRNA level of LBP was higher in P1 animals as compared to older animals, and that the kinetics of induction of cytokines and chemokines was significantly delayed in P1 as compared to P21 liver following LPS stimulation. Our data suggest that hepatic innate immunity is deficient in the neonates and undergo significant development during early postnatal life.
\end{abstract}

KEY WORDS: innate immunity; liver; LPS; development.

\section{INTRODUCTION}

Bacterial infection can lead to sepsis which may result in multiple organ failure or even mortality. Lipopolysaccharide (LPS), a complex glycolipid component of the cell wall of Gram-negative bacteria, is a potent activator of the innate immune response and a major cause of septic shock [1]. LPS is recognized by pattern recognition receptors (PRRs) such as LPS binding protein (LBP), CD14, and toll-like receptor (TLR)-4. The binding of LPS to TLR-4/myeloid differentiation protein (MD)-2 complex initiates an intracellular signaling network, eventually leading to increased expression of many inflammatory cytokines, such as tumor necrosis factor (TNF)- $\alpha$, interleukin (IL)- $1 \beta$, and IL-6, and chemokines, such as macrophage inflammatory protein (MIP)-1 $\beta$, MIP-2, monocyte chemotactic protein (MCP)-1, and keratinocyte-derived chemokine $(\mathrm{KC})[2,3]$.

Newborns are known to be more susceptible to infections by many microbes than adults. Many studies

\footnotetext{
${ }^{1}$ Department of Biological Sciences, Seton Hall University, 400 South Orange Avenue, South Orange, NJ 07079, USA

${ }^{2}$ To whom correspondence should be addressed at Department of Biological Sciences, Seton Hall University, 400 South Orange Avenue, South Orange, NJ 07079, USA. E-mail: heping.zhou@shu. edu
}

have suggested that the differences in their immune function may be the main contributing factors. For example, the polymorphonuclear leukocytes (PMNs) from preterm infants exhibit a much reduced antibacterial activity than those from adults, paralleled by a much lower level of CD14 expression [4]. Neonatal monocytes secrete a much reduced level of TNF- $\alpha$ than adult human peripheral blood monocytes (PBMCs) following LPS stimulation [5, 6]. Neonatal mice also have increased susceptibility and mortality to sepsis associated with an attenuated inflammatory response as compared to adults [7-9]. Taken together, these studies indicate a functional immaturity of the immune system at birth in the neonates.

As the largest solid organ in the body, liver receives $80 \%$ of its blood supply from the gut through the portal vein that is rich in bacterial products and environmental toxins, and functions as a major filter organ [10, 11]. Furthermore, liver is considered to be of major importance in innate immunity function, contributing to antiviral, antibacterial, and antitumor defenses [11, 12]. The liver consists of parenchymal hepatocytes and nonparenchymal cells, such as sinusoidal endothelial cells, Kupffer cells, and hepatic stellate cells [13]. Both parenchymal and non-parenchymal cells express CD14 and TLR-4, and can respond to LPS stimulation characterized by increased expression of inflammatory 
cytokines and chemokines [14-17]. Liver also contributes to systemic innate immunity through the biosynthesis of acute phase proteins such as LBP which is also a PRR and complement components such as $\mathrm{C} 3$ and $\mathrm{C} 9$ [11].

In this study, we aimed at investigating the postnatal development of hepatic innate immunity. We examined the constitutive expression of key innate immune mediators, specifically complement factors and PRRs during postnatal development, and compared the induction kinetics of cytokines and chemokines in the liver of postnatal day (P)1 and P21 animals following LPS treatment.

\section{MATERIALS AND METHODS}

\begin{abstract}
Animals
Young adult male and female Sprague-Dawley ${ }^{\circledR}$ rats were purchased from Harlan Inc. (Indianapolis, IN, USA), maintained in a temperature- and humiditycontrolled facility with a 12-h light/dark cycle, and fed with water and a standard rat diet ad libitum. The animals were given at least 1 week to acclimate to the animal facility before beginning the experiments. Animal studies were conducted with the approval from the Institutional Animal Care and Use Committee at Seton Hall University. The male rats were housed together with female rats for breeding, and the female rats with vaginal plugs were moved to separate cages under above-mentioned conditions [18]. For time-course studies, P1 or P21 pups were treated with $0.25 \mathrm{mg} / \mathrm{kg}$ LPS for 0 h, 0.5 h, 1 h, 2 h, 6 h, or 24 h via i.p. injection (four pups per group). At the end of treatment, the animals were sacrificed and their liver tissues were dissected to extract total RNA.
\end{abstract}

\section{Total RNA Extraction}

Total RNA from the dissected liver tissues was isolated using the TRIzol reagent (Invitrogen, Grand Island, NY, USA) according to manufacturer's instructions, dissolved in RNase-free water, and stored at $-80^{\circ} \mathrm{C}$.

\section{Semi-Quantitative Reverse Transcriptase- Polymerase Chain Reaction (RT-PCR) Assay}

After cDNA synthesis, PCR amplification was conducted using appropriate sense and antisense primers specific for rat $\beta$-actin (a housekeeping gene), IL-1 $\beta$, IL-6, TNF- $\alpha$, KC, MIP-1 $\beta$, MCP-1, MIP-2, TLR-4, CD14, MD-2, LBP, C3, and C9 [18, 19]. The sense and antisense primers for rat MD-2 were: 5'-GTG-GATCTG-CAA-CTC-CTC-CGA-TGC-3' and 5'-TGC-TGTGTT-GAC-AGC-CTC-CCC-T-3', respectively; the sense and antisense primers for rat MCP-1 were: $5^{\prime}$-ATG-ATCCCA-ATG-AGT-CGG-3' and 5'-ACA-GAA-GTG-CTTGAG-GTG-3', respectively; the sense and antisense primers for rat LBP were: 5'-CCG-GGT-TTA-CCACCA-GGC-CG-3' and 5'-TTC-GTG-ACC-ACG-CCAAGC-CG-3', respectively; the sense and antisense primers for rat $\mathrm{C} 3$ were: 5'-GGG-ACC-CCG-GTGGCT-CAG-AT-3' and 5'-GCT-GTC-AGC-CAG-GTGCTG-GG-3', respectively; and the sense and antisense primers for rat C9 were: 5'-TGC-CGT-GAC-CGG-GTGGTA-GAA-3' and 5'-TGT-CAG-CCT-TGG-TTT-CATAGG-CCA-GA-3', respectively. The PCR reactions were carried out by heating the samples to $94^{\circ} \mathrm{C}$ for $5 \mathrm{~min}$, followed by appropriate cycles of denaturation at $94^{\circ} \mathrm{C}$ for $30 \mathrm{~s}$, annealing at $57^{\circ} \mathrm{C}$ for $30 \mathrm{~s}$, and extension at $72^{\circ} \mathrm{C}$ for $30 \mathrm{~s}$. After the final cycle, the PCR reactions were extended for another $7 \mathrm{~min}$. The optimum number of cycles were 25 cycles for C 3 and LBP; 26 cycles for TNF- $\alpha$ and CD14; 27 cycles for IL-1 $\beta ; 28$ cycles for IL$6, \mathrm{KC}$, and MCP-1; 29 cycles for C9, MIP-1 $\beta$, and MD$2 ; 30$ cycles for TLR-4 and MIP-2; and 21 cycles for $\beta$ actin. After running PCR products on a $2.0 \%$ agarose gel, the gel image was recorded using a UVP GelDoc$\mathrm{It}^{\mathrm{TM}}$ imaging system (UVP, Upland, CA, USA) and digitized using VisionWorks ${ }^{\mathrm{TM}}$ LS software (UVP). The relative intensities for the genes of interest were normalized to the intensity of $\beta$-actin in the same sample.

\section{Statistical Analysis}

All data were analyzed using one-way analysis of variance (ANOVA) followed by Newman-Keuls posttest (GraphPad Prizm, La Jolla, CA, USA) and presented as means \pm SE. Results with $p<0.05$ were considered statistically significant.

\section{RESULTS}

\section{Constitutive Hepatic Expression of Acute Phase Proteins During Postnatal Development}

Liver is critical for producing important acute phase immune mediators such as complement components 

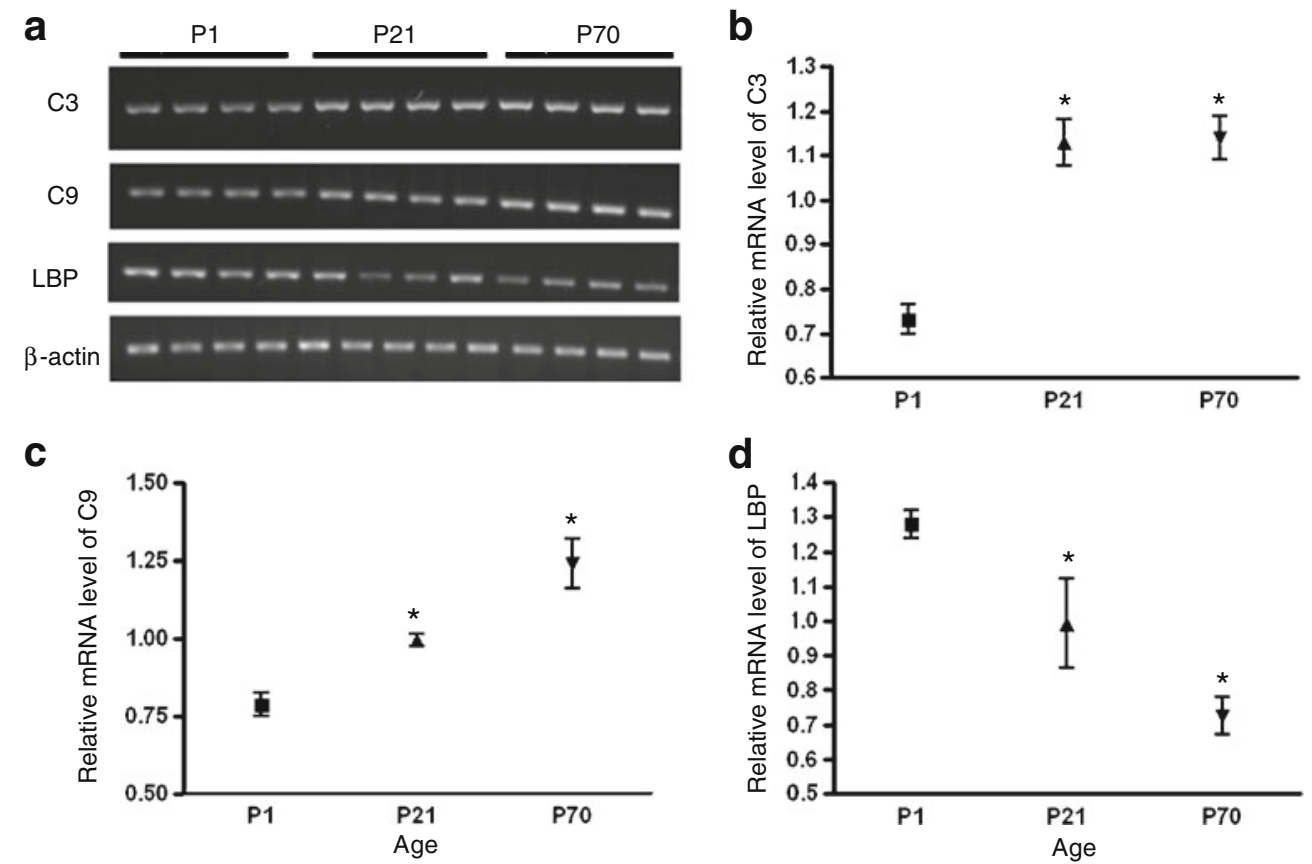

Fig. 1. Basal mRNA expression levels of $\mathrm{C} 3(\mathbf{a}, \mathbf{b}), \mathrm{C} 9$ (a, c), and LBP (a, d) in the liver of P1, P21, and P70 animals. a Representative RT-PCR of C3, C9, LBP, and $\beta$-actin. b Quantitation of RT-PCR of C3 normalized to $\beta$-actin. $\mathbf{c}$ Quantitation of RT-PCR of C9 normalized to $\beta$-actin. $\mathbf{d}$ Quantitation of RT-PCR of LBP normalized to $\beta$-actin. Data were presented as means \pm SE; $n=4$. Asterisk represents significant difference from P1 group at $p<0.05$ (one-way ANOVA followed by Newman-Keuls post-test).

a

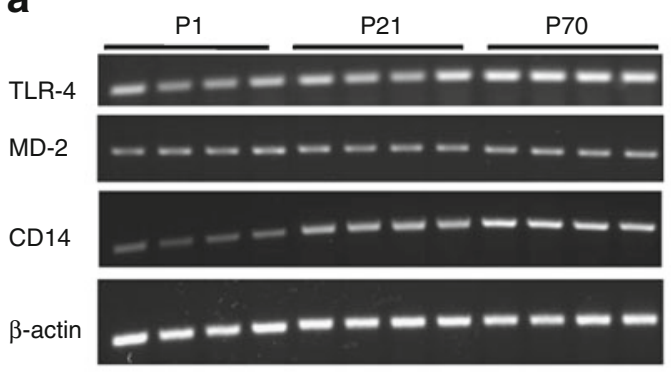

C

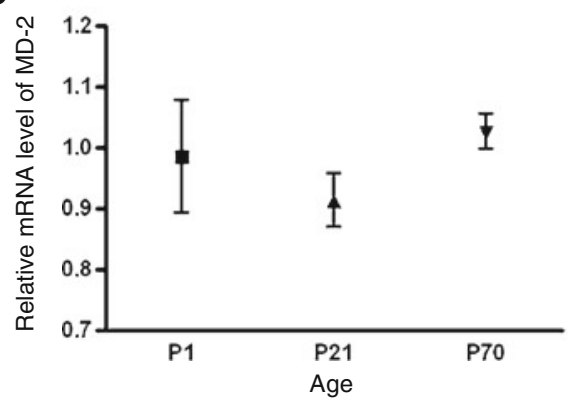

b

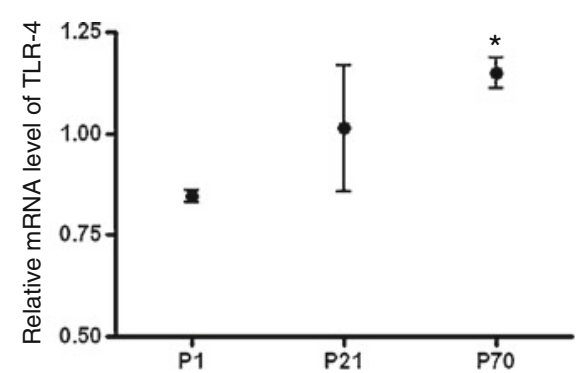

d

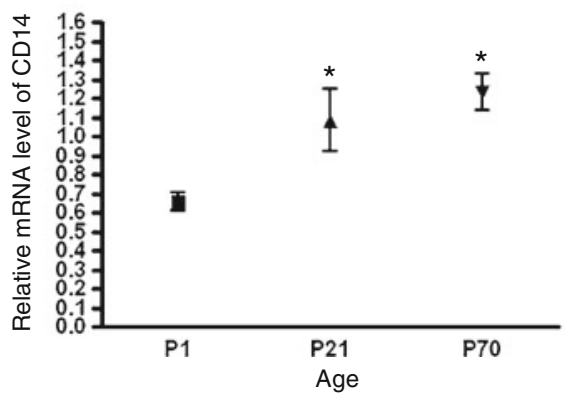

Fig. 2. Basal mRNA expression levels of TLR-4 (a, b), MD-2 (a, c), and CD14 (a, d) in the liver of P1, P21, and P70 animals. a Representative RTPCR of TLR-4, MD-2, CD14, and $\beta$-actin. b Quantitation of RT-PCR of TLR-4 normalized to $\beta$-actin. $\mathbf{c}$ Quantitation of RT-PCR of MD-2 normalized to $\beta$-actin. d Quantitation of RT-PCR of CD14 normalized to $\beta$-actin. Data were presented as means \pm SE; $n=4$. Asterisk represents significant difference from P1 group at $p<0.05$ (one-way ANOVA followed by Newman-Keuls post-test). 
[11], we therefore examined the constitutive expression levels of C3 and C9 in the liver of P1, P21, and P70 animals. The mRNA levels of $\mathrm{C} 3$ and $\mathrm{C} 9$ in the liver of P1 were significantly lower than that in P21 and P70. While the mRNA level of $\mathrm{C} 3$ in P21 liver was comparable to that in P70 liver, the mRNA level of C9 in P21 liver was significantly lower than that in P70 liver (Fig. 1b, c). In contrast, the expression of another acute phase protein LBP, also a soluble pattern recognition receptor for LPS, was higher in P1 liver and gradually decreased during postnatal development (Fig. 1d).

\section{Constitutive Hepatic Expression of PRRs During Postnatal Development}

LPS is recognized by PRRs such as LBP and CD14, which then transfers LPS to TLR-4/MD-2 complex to initiate the intracellular signaling network $[2,3]$. We therefore examined the constitutive expression of these upstream mediators of LPS-initiated signaling pathway, namely TLR-4, MD-2, and CD14, in the liver of P1, P21, and P70 animals. While MD-2 mRNA was not significantly altered in P1, P21, and P70 liver (Fig. 2c), the mRNA levels of TLR-4 (Fig. 2b) and CD14 (Fig. 2d) were lower in P1 liver and increased during postnatal development.

\section{Kinetics of Induction of Pro-inflammatory Cytokines in the Liver of P1 Animals}

Pro-inflammatory cytokines play key roles in the inflammatory process [20], therefore, we examined the kinetics of induction of pro-inflammatory cytokines, namely $\mathrm{TNF}-\alpha$, IL- $1 \beta$, and IL-6, in the liver of P1 animals following LPS treatment. In the liver of P1 animals, the mRNA levels of TNF- $\alpha$ (Fig. 3b) and IL$1 \beta$ (Fig. 3c) were significantly elevated by $2 \mathrm{~h}$, remained elevated at $6 \mathrm{~h}$, and significantly decreased by $24 \mathrm{~h}$ following LPS stimulation, and the mRNA level of IL-6 was significantly increased at $6 \mathrm{~h}$ and declined to basal level by $24 \mathrm{~h}$ following LPS treatment (Fig. 3d).
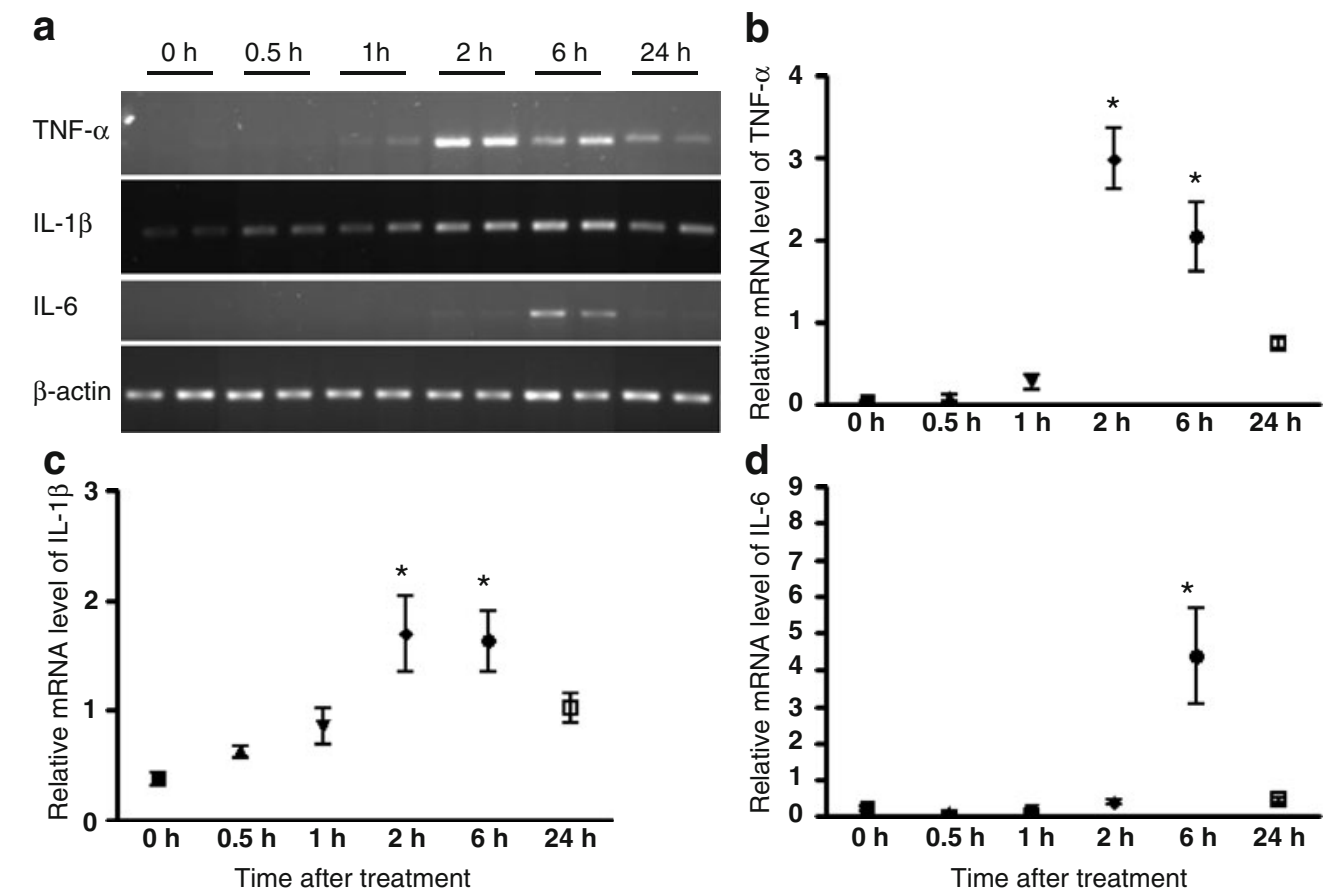

Fig. 3. Time course of TNF- $\alpha(\mathbf{a}, \mathbf{b}), \operatorname{IL}-1 \beta(\mathbf{a}, \mathbf{c})$, and IL-6 (a, d) expression in the liver of P1 animals at $0 \mathrm{~h}, 0.5 \mathrm{~h}, 1 \mathrm{~h}, 2 \mathrm{~h}, 6 \mathrm{~h}$, and $24 \mathrm{~h}$ following LPS stimulation. a Representative RT-PCR of TNF- $\alpha$, IL- $1 \beta$, IL- 6 , and $\beta$-actin. b Quantitation of RT-PCR of TNF- $\alpha$ normalized to $\beta$-actin. $\mathbf{c}$ Quantitation of RT-PCR of IL- $1 \beta$ normalized to $\beta$-actin. $\mathbf{d}$ Quantitation of RT-PCR of IL-6 normalized to $\beta$-actin. Data were presented as means \pm $\mathrm{SE} ; n=4$. Asterisk represents significant difference from $0 \mathrm{~h}$ group at $p<0.05$ (one-way ANOVA followed by Newman-Keuls post-test). 


\section{Kinetics of Induction of Pro-inflammatory Cytokines in the Liver of P21 Animals}

We then examined the kinetics of induction of TNF- $\alpha$, IL- $1 \beta$, and IL- 6 in the liver of P2 1 animals following LPS treatment. The mRNA level of TNF- $\alpha$ (Fig. 4b) was significantly elevated by $0.5 \mathrm{~h}$, peaked at $1 \mathrm{~h}$, started to decline by $6 \mathrm{~h}$, and returned to basal level following LPS stimulation; the mRNA level of IL-1 $\beta$ (Fig. 4c) was significantly elevated by $0.5 \mathrm{~h}$, peaked at $2 \mathrm{~h}$, started to decline by $6 \mathrm{~h}$, and returned to basal level by $24 \mathrm{~h}$ following LPS stimulation; and the mRNA level of IL-6 (Fig. 4d) was significantly elevated by $1 \mathrm{~h}$, peaked at $2 \mathrm{~h}$, and returned to basal level by $6 \mathrm{~h}$ following LPS stimulation. These data suggest that the kinetics of LPS-induced expression of pro-inflammatory cytokines in the liver of $\mathrm{P} 1$ animals was generally delayed as compared to that in the liver of P21 animals.

\section{Kinetics of Induction of Anti-inflammatory Cytokine in the Liver of P1 and P21 Animals}

Anti-inflammatory cytokines play key roles in quenching the inflammatory response [20]; therefore, we examined the kinetics of induction of IL10, an anti-inflammatory cytokine, in the liver of P1 and P21 animals following LPS treatment. The mRNA level of IL-10 was significantly increased at $2 \mathrm{~h}$, started to decrease by $6 \mathrm{~h}$, and returned to basal level by $24 \mathrm{~h}$ following LPS stimulation in the liver of P1 animals (Fig. 5a). In contrast, the mRNA level of IL-10 was significantly increased at $0.5 \mathrm{~h}$, remained elevated through $6 \mathrm{~h}$, and returned to basal level by $24 \mathrm{~h}$ following LPS stimulation in the liver of P21 animals (Fig. 5b). These data suggest that the kinetics of LPS-induced expression of IL-10 in the liver of P1 animals was also delayed as compared to that in the liver of P21 animals.
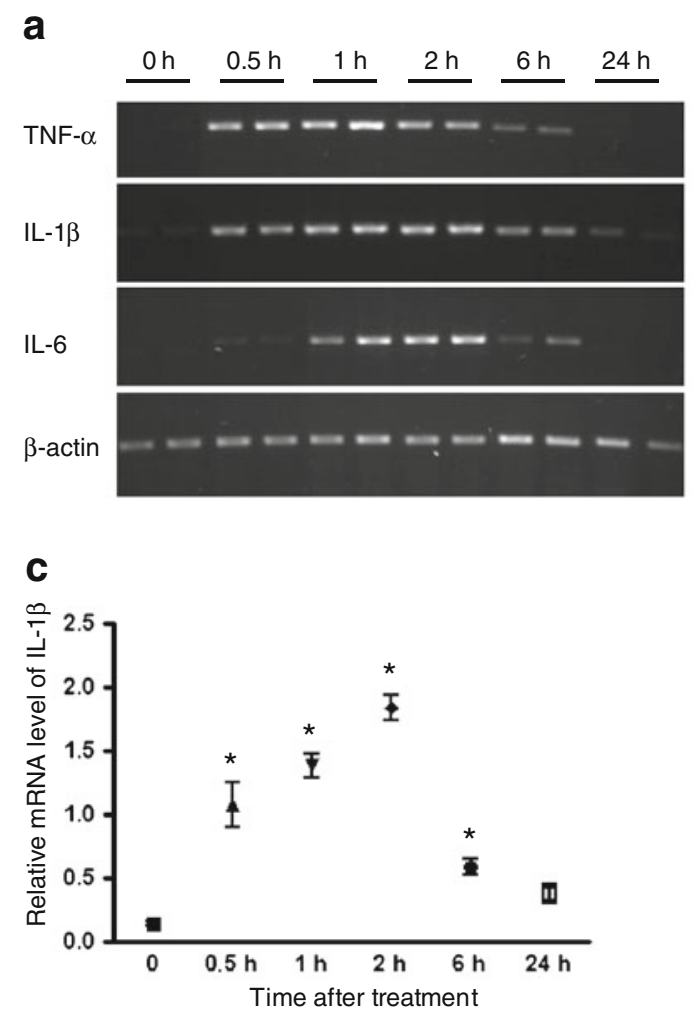

b
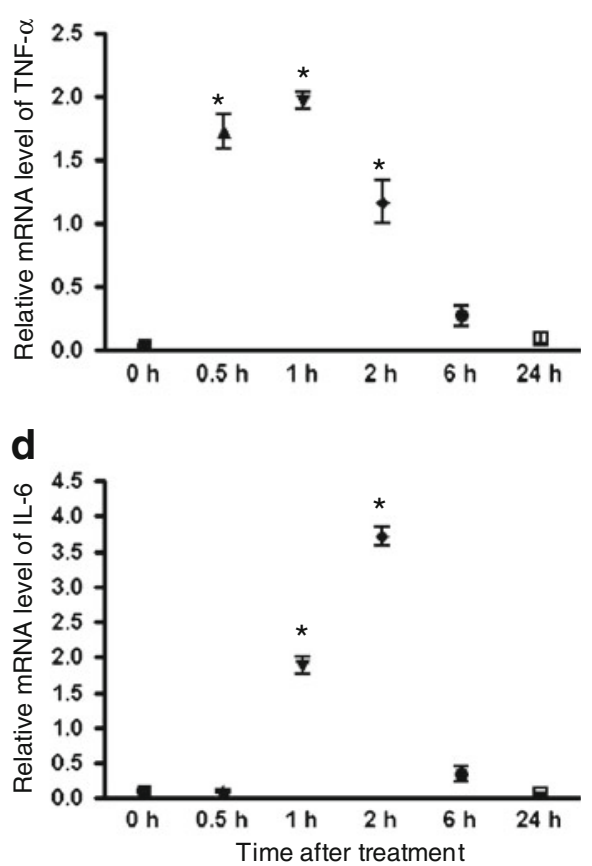

Fig. 4. Time course of TNF- $\alpha$ (a, b), IL-1 $\beta$ (a, c), and IL-6 (a, d) expression in the liver of P21 animals at 0 h, 0.5 h, 1 h, 2 h, 6 h, and 24 h following LPS stimulation. a Representative RT-PCR of TNF- $\alpha$, IL- $1 \beta$, IL- 6 , and $\beta$-actin. b Quantitation of RT-PCR of TNF- $\alpha$ normalized to $\beta$-actin. $\mathbf{c}$ Quantitation of RT-PCR of IL-1 $\beta$ normalized to $\beta$-actin. d Quantitation of RT-PCR of IL- 6 normalized to $\beta$-actin. Data were presented as means \pm $\mathrm{SE} ; n=4$. Asterisk represents significant difference from $0 \mathrm{~h}$ group at $p<0.05$ (one-way ANOVA followed by Newman-Keuls post-test). 
a
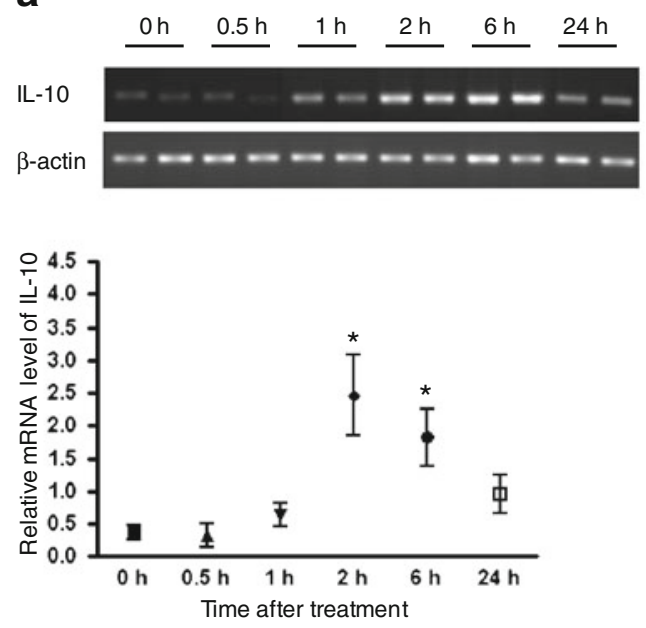

b
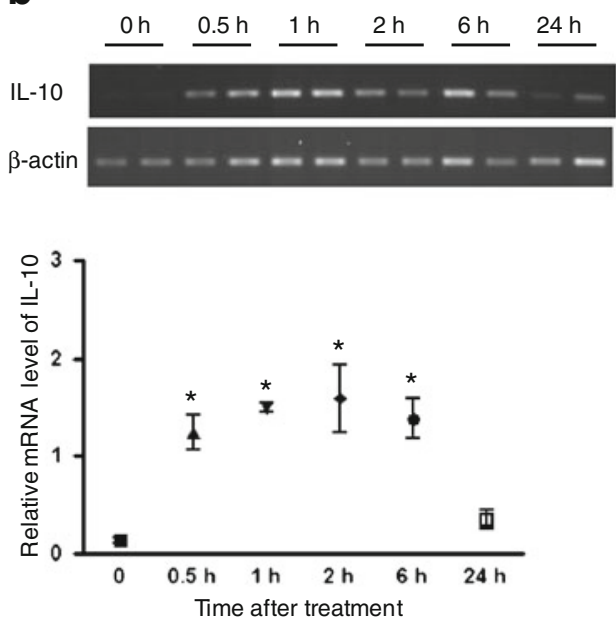

Fig. 5. Time course of IL-10 expression in the liver of P1 (a) and P21 (b) animals at 0 h, 0.5 h, 1 h, 2 h, 6 h, and 24 h following LPS stimulation. Quantitation of IL-10 was normalized to $\beta$-actin. Data were presented as means \pm SE; $n=4$. Asterisk represents significant difference from $0 \mathrm{~h}$ group at $p<0.05$ (one-way ANOVA followed by Newman-Keuls post-test).
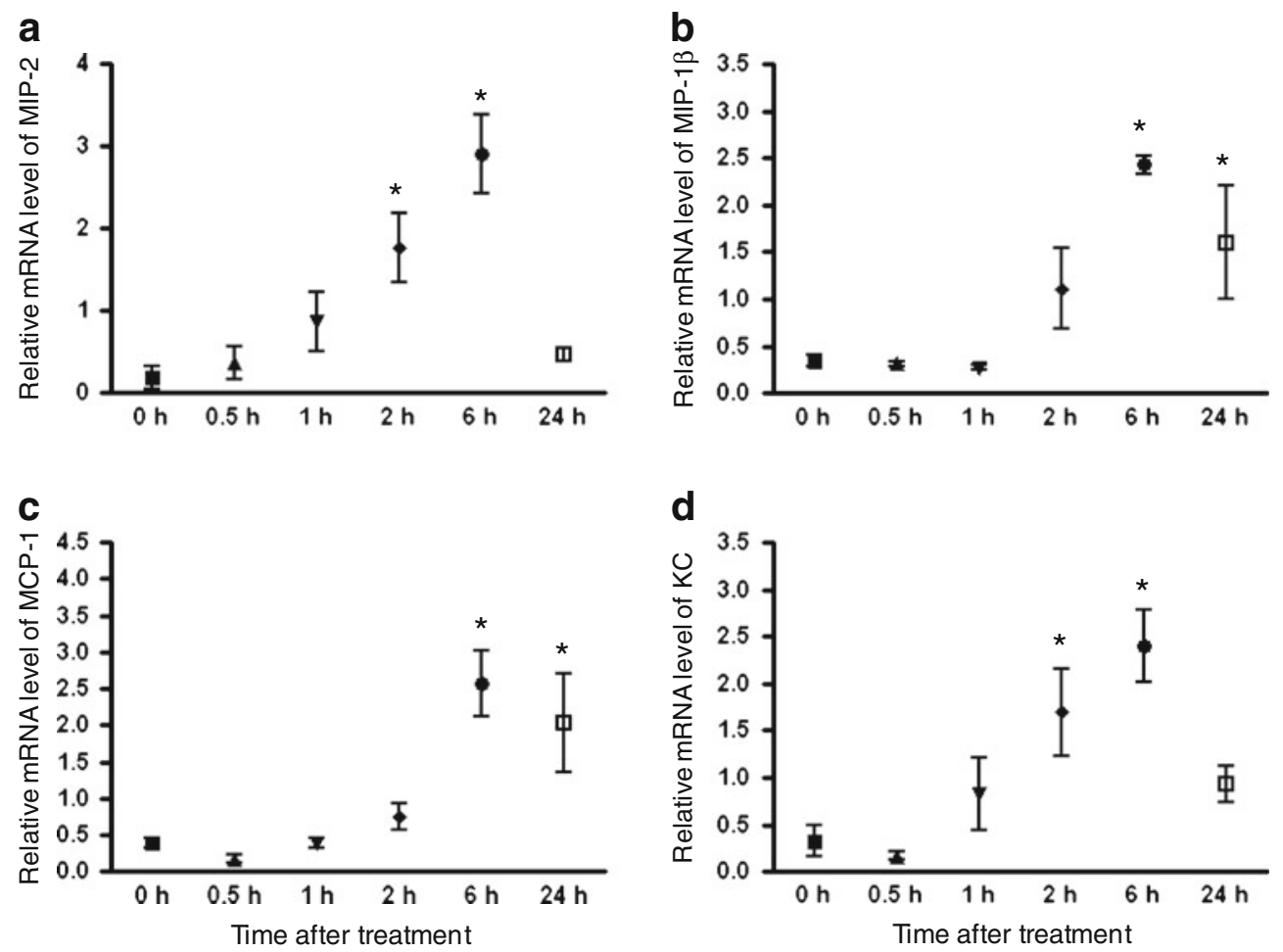

Fig. 6. Time course of MIP-2 (a), MIP-1 $\beta$ (b), MCP-1 (c), and KC (d) expression in the liver of P1 animals at 0 h, 0.5 h, 1 h, 2 h, 6 h, and 24 h following LPS stimulation. Quantitation of RT-PCR of these chemokines was normalized to $\beta$-actin. Data were presented as means \pm SE; $n=4$. Asterisk represents significant difference from 0 h group at $p<0.05$ (one-way ANOVA followed by Newman-Keuls post-test). 


\section{Kinetics of Induction of Chemokines in the Liver of P1 Animals}

We then examined LPS-induced expression of chemokines, namely MIP-1 $\beta$, MIP-2, MCP-1, and KC, in the liver of $\mathrm{P} 1$ animals. In the liver of $\mathrm{P} 1$ animals, the mRNA levels of MIP-1 $\beta$ (Fig. 6b) and MCP-1 (Fig. 6c) were significantly elevated at $6 \mathrm{~h}$ and started to decrease by $24 \mathrm{~h}$ following LPS stimulation; and the mRNA levels of MIP-2 (Fig. 6a) and KC (Fig. 6d) were significantly elevated at $2 \mathrm{~h}$, peaked at $6 \mathrm{~h}$, and returned to basal level by $24 \mathrm{~h}$ following LPS stimulation.

\section{Kinetics of Induction of Chemokines in the Liver of P21 Animals}

We then examined LPS-induced expression of MIP-1 $\beta$, MIP-2, MCP-1, and KC in the liver of P21 animals. The mRNA level of MIP-2 (Fig. 7a) was significantly elevated at $0.5 \mathrm{~h}$, continued to increase at $1 \mathrm{~h}$, remained high at $2 \mathrm{~h}$, and returned to basal level by $6 \mathrm{~h}$ following LPS stimulation; and the mRNA levels of MIP-1 $\beta$ (Fig. 7b), MCP-1 (Fig. 7c), and KC (Fig. 7d) were significantly elevated at $0.5 \mathrm{~h}$, peaked at $2 \mathrm{~h}$, started to decline by $6 \mathrm{~h}$, and returned to basal level by $24 \mathrm{~h}$ following LPS stimulation. These data suggest that the kinetics of LPS-induced expression of chemokines in the liver of P1 animals was generally delayed as compared to that in the liver of P21 animals.

\section{DISCUSSION}

During early postnatal period, liver undergoes functional maturation from a major hematopoietic tissue to a central organ for intermediary metabolism with important exocrine, endocrine, and innate immune functions [21, 22]. Shortly after birth, neonatal liver must have the capacity to deal with bacteria derived from the intestinal tract besides a range of hormones, food antigens, and complex molecules as colonies of bacteria start to establish themselves in the intestine and develop a stable microflora in the large bowel [23]. The innate immune response is the first line of defense against a diverse range of microbes, and the liver
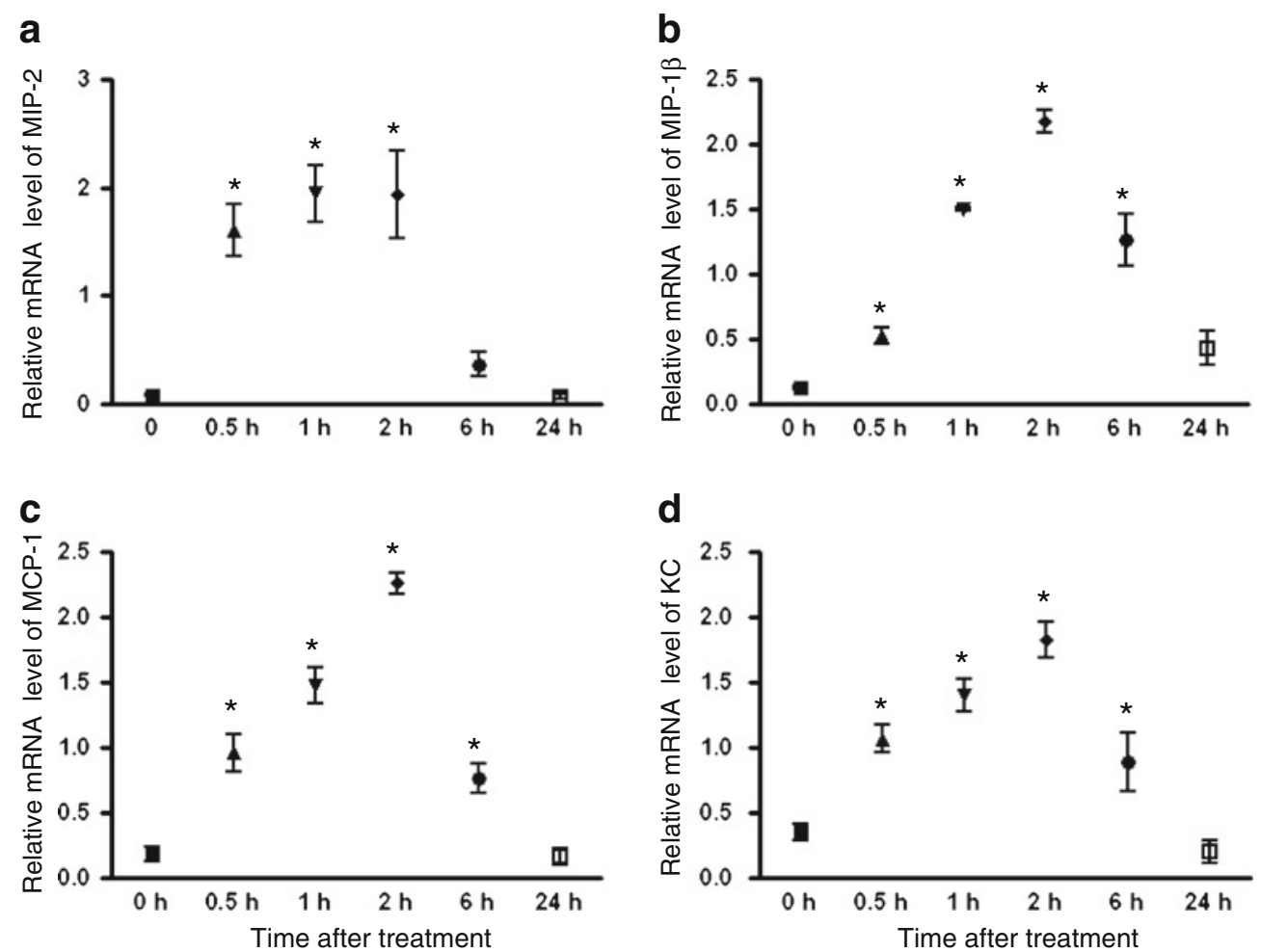

Fig. 7. Time course of MIP-2 (a), MIP-1 $\beta$ (b), MCP-1 (c), and KC (d) expression in the liver of P21 animals at 0 h, 0.5 h, 1 h, 2 h, 6 h, and 24 h following LPS stimulation. Quantitation of RT-PCR of these chemokines was normalized to $\beta$-actin. Data were presented as means \pm SE; $n=4$. Asterisk represents significant difference from $0 \mathrm{~h}$ group at $p<0.05$ (one-way ANOVA followed by Newman-Keuls post-test). 
produces important innate immune mediators such as acute phase proteins, complement factors, cytokines, and chemokines [13]. Therefore, we delineated the agedependent maturation of hepatic innate immunity in this study. We found that the mRNA levels of C3 and C9 in P1 liver were significantly reduced compared to P21 and P70 liver, which may contribute to impaired opsonization potential in the neonates. We also found that the kinetics of the induction of cytokines and chemokines in P1 liver was significantly delayed as compared to P21 liver. These data suggest that the initial hepatic inflammatory response in the neonates may not be sufficient to combat bacterial infections. Consistently, some premature newborn infants that are affected by hyperacute fulminant pneumonia due to Gram-positive (Group B Streptococcus, in particular) or Gram-negative (Escherichia coli and others) bacteria are actually found to be deficient in their initial acute phase response [24].

There is increasing evidence that the decreased level of CD14 and the elevated level of LBP may account for the delayed induction of cytokines and chemokines in P1 liver. CD14 and LBP are known to play key roles in promoting innate immunity to Gramnegative bacteria by transferring LPS to TLR4/MD-2 receptor signaling complex. LBP has been suggested to play a biphasic role by enhancing the response to LPS at low concentration and inhibiting LPS response at high concentration $[25,26]$. Consistently, LBP treatment has been reported to suppress LPS-induced IL-1 $\beta$ expression by human gingival fibroblasts [27]. It is likely that the elevated level of LBP in P1 liver may suppress the hepatic response to LPS. Furthermore, it has been reported that LPS-induced TLR-4/MD-2 dimerization occurs only in membrane-associated CD14-expressing cells and that this dimerization prompts rapid signaling during innate immune responses [28]. Therefore, lower CD14 expression may lead to lower TLR-4/MD-2 complex formation and therefore delayed innate immune signaling in P1 liver. Additionally, diminished TLR-4 mRNA level in P1 liver may also contribute to lower TLR-4/MD-2 complex formation, thereby delaying TLR-4-mediated response to LPS.

In summary, our studies showed that the mRNA expression of C3, C9, CD14, and TLR-4 was lower in P1 liver and the mRNA level of LBP was higher in P1 liver as compared to older animals. We also found that the kinetics of induction of cytokines and chemokines was significantly delayed in P1 liver as compared to P21 liver following LPS stimulation. The decreased production of complement components and delayed TLR-4 response in neonatal rats may protect the host from inflammation but may also leave them more susceptible to local hepatic and systemic infections. Insight into the kinetics of induction of inflammatory mediators in the neonates may help in designing new strategies to modulate the maturation of their innate immune system, and to prevent and/or treat infections during this vulnerable period.

\section{ACKNOWLEDGMENTS}

This work was supported in part by the University Research Council Award and the National Institute of Health Grant R15-HD065643 to H.Z.

Open Access. This article is distributed under the terms of the Creative Commons Attribution Noncommercial License which permits any noncommercial use, distribution, and reproduction in any medium, provided the original author(s) and source are credited.

\section{REFERENCES}

1. Alexander, C., and E.T. Rietschel. 2001. Bacterial lipopolysaccharides and innate immunity. Journal of Endotoxin Research 7: $167-202$.

2. Liu, Y.W., C.C. Chen, H.P. Tseng, and W.C. Chang. 2006. Lipopolysaccharide-induced transcriptional activation of interleukin-10 is mediated by MAPK- and NF-kappaB-induced CCAAT/ enhancer-binding protein delta in mouse macrophages. Cellular Signalling 18: 1492-1500.

3. Palsson-McDermott, E.M., and L.A. O'Neill. 2004. Signal transduction by the lipopolysaccharide receptor, Toll-like receptor-4. Immunology 113: 153-162.

4. Henneke, P., I. Osmers, K. Bauer, N. Lamping, H.T. Versmold, and R.R. Schumann. 2003. Impaired CD14-dependent and independent response of polymorphonuclear leukocytes in preterm infants. Journal of Perinatal Medicine 31: 176-183.

5. Yan, S.R., G. Qing, D.M. Byers, A.W. Stadnyk, W. Al-Hertani, and R. Bortolussi. 2004. Role of MyD88 in diminished tumor necrosis factor alpha production by newborn mononuclear cells in response to lipopolysaccharide. Infection and Immunity 72: 1223-1229.

6. Levy, O. 2005. Innate immunity of the human newborn: distinct cytokine responses to LPS and other Toll-like receptor agonists. Journal of Endotoxin Research 11: 113-116.

7. Bogaert, D., D. Weinberger, C. Thompson, M. Lipsitch, and R. Malley. 2009. Impaired innate and adaptive immunity to Streptococcus pneumoniae and its effect on colonization in an infant mouse model. Infection and Immunity 77: 1613-1622.

8. Wynn, J.L., P.O. Scumpia, M.J. Delano, K.A. O'Malley, R. Ungaro, A. Abouhamze, and K.L. Moldawer. 2007. Increased mortality and altered immunity in neonatal sepsis produced by generalized peritonitis. Shock 28: 675-683. 
9. Wynn, J.L., P.O. Scumpia, R.D. Winfield, M.J. Delano, K. KellyScumpia, T. Barker, R. Ungaro, O. Levy, and L.L. Moldawer. 2008. Defective innate immunity predisposes murine neonates to poor sepsis outcome but is reversed by TLR agonists. Blood 112: $1750-1758$.

10. Schwabe, R.F., E. Seki, and D.A. Brenner. 2006. Toll-like receptor signaling in the liver. Gastroenterology 130: 1886-1900.

11. Gao, B., W.I. Jeong, and Z. Tian. 2008. Liver: an organ with predominant innate immunity. Hepatology 47: 729-736.

12. Racanelli, V., and B. Rehermann. 2006. The liver as an immunological organ. Hepatology 43: S54-S62.

13. Kmiec, Z. 2001. Cooperation of liver cells in health and disease. Advances in Anatomy, Embryology and Cell Biology 161(III-XIII): $1-151$.

14. Su, G.L., K. Dorko, S.C. Strom, A.K. Nussler, and S.C. Wang. 1999. CD14 expression and production by human hepatocytes. Journal of Hepatology 31: 435-442.

15. Hayashi, T., M. Kishiwada, K. Fujii, H. Yuasa, J. Nishioka, M. Ido, E.C. Gabazza, and K. Suzuki. 2006. Lipopolysaccharide-induced decreased protein $\mathrm{S}$ expression in liver cells is mediated by MEK/ ERK signaling and NFkappaB activation: involvement of membrane-bound CD14 and toll-like receptor-4. Journal of Thrombosis and Haemostasis 4: 1763-1773.

16. Vodovotz, Y., S. Liu, C. McCloskey, R. Shapiro, A. Green, and T. R. Billiar. 2001. The hepatocyte as a microbial product-responsive cell. Journal of Endotoxin Research 7: 365-373.

17. Garcia-Lazaro, J.F., F. Thieringer, S. Luth, P. Czochra, E. Meyer, I. B. Renteria, P.R. Galle, A.W. Lohse, J. Herkel, and S. Kanzler. 2005. Hepatic over-expression of TGF-betal promotes LPSinduced inflammatory cytokine secretion by liver cells and endotoxemic shock. Immunology Letters 101: 217-222.

18. Surriga, O., A. Ortega, V. Jadeja, A. Bellafronte, N. Lasala, and H. Zhou. 2009. Altered hepatic inflammatory response in the offspring following prenatal LPS exposure. Immunology Letters 123: 88-95.
19. Lasala, N., and H. Zhou. 2007. Effects of maternal exposure to LPS on the inflammatory response in the offspring. Journal of Neuroimmunology 189: 95-101.

20. Moore, K.W., R. de Waal Malefyt, R.L. Coffman, and A. O'Garra. 2001. Interleukin-10 and the interleukin-10 receptor. Annual Review of Immunology 19: 683-765.

21. Orkin, S.H. 1996. Development of the hematopoietic system. Current Opinion in Genetics \& Development 6: 597-602.

22. Miyajima, A., T. Kinoshita, M. Tanaka, A. Kamiya, Y. Mukouyama, and T. Hara. 2000. Role of Oncostatin M in hematopoiesis and liver development. Cytokine \& Growth Factor Reviews 11: 177-183.

23. Beath, S.V. 2003. Hepatic function and physiology in the newborn. Seminars in Neonatology 8: 337-346.

24. Suffredini, A.F., G. Fantuzzi, R. Badolato, J.J. Oppenheim, and N. P. O'Grady. 1999. New insights into the biology of the acute phase response. Journal of Clinical Immunology 19: 203-214.

25. Kitchens, R.L., and P.A. Thompson. 2005. Modulatory effects of $\mathrm{SCD} 14$ and LBP on LPS-host cell interactions. Journal of Endotoxin Research 11: 225-229.

26. Thompson, P.A., P.S. Tobias, S. Viriyakosol, T.N. Kirkland, and R. L. Kitchens. 2003. Lipopolysaccharide (LPS)-binding protein inhibits responses to cell-bound LPS. The Journal of Biological Chemistry 278: 28367-28371.

27. Ren, L., Z.Q. Jiang, Y. Fu, W.K. Leung, and L. Jin. 2009. The interplay of lipopolysaccharide-binding protein and cytokines in periodontal health and disease. Journal of Clinical Periodontology 36: 619-626.

28. Tsukamoto, H., K. Fukudome, S. Takao, N. Tsuneyoshi, and M. Kimoto. 2010. Lipopolysaccharide-binding protein-mediated Toll-like receptor 4 dimerization enables rapid signal transduction against lipopolysaccharide stimulation on membraneassociated CD14-expressing cells. International Immunology 22: 271-280. 